\title{
Utilização de Dietas Úmidas e de Rações e Água de Bebida com Edulcorante para Leitões Desmamados aos 21 Dias de Idade e Efeitos sobre o Desenvolvimento Histológico e Enzimático Intestinal
}

\author{
Caio Abércio da Silva ${ }^{1}$, Rodolfo Nascimento Kronka ${ }^{2}$, Maria Cristina Thomaz ${ }^{2}$, \\ Sérgio Nascimento Kronka ${ }^{2}$, Wilson Castillo Soto ${ }^{3}$, Luís Euquério de Carvalho ${ }^{3}$
}

\begin{abstract}
RESUMO - Um experimento foi realizado com leitões desmamados visando avaliar os efeitos de oito tratamentos, correspondentes à combinação dos fatores, apresentações de ração (seca e úmida), tipos de ração (sem e com edulcorante) e tipos de água de consumo (sem e com edulcorante) sobre o desenvolvimento morfológico e enzimático intestinal. Foram avaliadas a altura das vilosidades (V), a profundidade das criptas $(\mathrm{C})$ e a relação altura das vilosidades e profundidade das criptas (V:C) do duodeno e do jejuno, o conteúdo de proteína na mucosa do jejuno, e as atividades enzimáticas (UA) da maltase, sacarase e dipeptidase. Utilizaram-se 32 leitões machos castrados, Large White x Landrace, desmamados aos 21 dias, submetidos aos tratamentos durante oito dias. O delineamento experimental foi em blocos casualizados, com oito tratamentos, fatorial 2 x 2 x 2, com quatro repetições. Foram observadas diferenças para a altura das vilosidades do duodeno para os grupos tratados com dieta úmida e ração com edulcorante e para a relação $\mathrm{V}$ :C do duodeno para os animais que receberam ração com edulcorante. Houve diferença para a UA da sacarase e da maltase para os grupos que receberam água sem edulcorante. As características histológicas foram favorecidas pelas dietas úmidas, o que pode sugerir que esta apresentação foi menos agressiva ao trato digestivo. Para os demais fatores os resultados contrariaram as expectativas de que o tratamento água com edulcorante melhoraria a qualidade do epitélio intestinal. A fase crítica pela qual os leitões foram submetidos, possivelmente, comprometeu os resultados.
\end{abstract}

Palavras-chave: água, edulcorante, enzima, intestino, ração úmida, suíno

\section{Wet Feeding and Water and Rations with Sweetener for Weaned 21-d Old Piglets and its Effects on Intestinal Histology and Enzymatic Development}

ABSTRACT - An experiment was conducted with piglets allocated in eight treatments combinations with different types of diet (dry and wet), rations (with and without sweetener) and two types of drinking water (with and without sweetener), offered after weaning to study the effects on histology and intestine enzymatic development. Intestinal villi height, crypt depth, and relation between villi height and crypt depth of duodenum and jejunum, jejunum protein content and enzyme activity of maltase, sucrase and dipeptidase were evaluated. Thirty two Large White $\mathrm{x}$ Landrace castrated male piglets weaned at 21 days were utilized. At weaning the piglets were allocated to the treatments during 8 days. It was used a randomized block to study a factorial $2 \times 2 \times 2$ with four replications. The results showed differences in duodenum height of villi for wet diet and ration with sweetener. Probably, the wet diet was better than dry diet, improving the quality of the intestinal tract. Also significant differences were found in the relationship between duodenum villi height and crypt depth for ration with sweetener. There were differences in enzyme activity of sucrase and maltase for water without sweetener. These results were different from initial hipothesis, where the water with sweetener would be better to improve the intestinal development. The experiment was conducted during a critical phase after weaning. It is possible that the results were influenced by this period.

Key Words: enzyme, intestine, histology, swine, water, wet feeding

\section{Introdução}

Leitões desmamados às três e quatro semanas de idade passam por uma fase crítica na primeira semana pós-desmame (MAENZ et al., 1993), resultando em mudanças na histologia e na morfologia intestinal com comprometimento da digestão (PEKAS, 1991).
Comumente, o baixo consumo alimentar no pósdesmame reduz a capacidade do leitão para digerir alimento, determinando alterações enzimáticas no sistema digestivo e favorecendo a danos na parede intestinal com comprometimento imediato e, às vezes, persistente do desempenho (CERA et al., 1988; 1990; TOPLIS e TIBBLE, 1994). BERTO (1993),

\footnotetext{
${ }^{1}$ Médico Veterinário. Doutor. Universidade Estadual de Londrina. Departamento de Zootecnia. Londrina, PR.CEP 86051 970 E.mail: casilva@npd.uel.br

2 Engenheiros-Agrônomos. Doutores. Universidade Estadual Paulista - Faculdade de Ciências Agrárias e Veterinárias - Campus de Jaboticabal 3 Alunos de Pós-Graduação em Zootecnia da UNESP - Faculdade de Ciências Agrárias e Veterinárias - Campus de Jaboticabal.
} 
não obstante, obteve resultados positivos sobre o aumento de consumo de ração nas primeiras semanas pós-desmame, utilizando rações complexas. KELLY et al. (1991b) e MAKKING et al. (1994) demonstraram existir uma relação positiva e benéfica entre o consumo de ração após o desmame, a qualidade morfológica intestinal e o crescimento corporal. WHITTEMORE (1993), objetivando estimular o consumo de alimento no pós-desmame, verificou os efeitos positivos dos flavorizantes na nutrição de leitões, promovendo efetivamente o consumo, desenvolvendo o sistema enzimático e melhorando conseqüentemente o desempenho.

A utilização de dietas úmidas ou líquidas para leitões desmamados vem representando outro recurso de manejo alimentar na indução do consumo, dado os importantes resultados apresentados (HEIMIG, 1996; FREITAS et al., 1997).

Nesse sentido, DEPREZ et al. (1987), em um estudo histopatológico das vilosidades intestinais de leitões desmamados aos 28 dias, tratados com dietas secas e líquidas, observaram extensas vantagens para a alimentação líquida. Leitões tratados com dietas secas apresentaram redução na altura das vilosidades.

Considerando os aspectos ultra-estruturais do jejuno e do final do íleo, TEODORO (1997), contradizendo os estudos anteriores, não observaram diferença entre dietas fareladas e extrusadas secas e extrusadas úmidas para leitões desmamados aos 21 dias.

Os experimentos com a indução indireta do consumo de ração pelo uso de edulcorantes na água de bebida determinaram resultados controversos (STOCKILL, 1990; MAENZ et al., 1993). Segundo CUNHA (1977)e SOBESTIANSKY e WENTZ (1985), o estímulo para que leitões recém-desmamados venham ingerir mais água ajuda a prevenir a desidratação provocada pelas diarréias, aumenta o consumo de ração e melhora a digestibilidade e o desempenho geral.

STOCKILL (1990) obteve importante aumento no consumo de água nos três primeiros dias após o desmame, quando foi adicionada sacarina sódica na água. Foram obtidos consumos 2 a 3 vezes superiores ao tratamento isento de sacarina. Como consequiência, os resultados foram também positivos sobre o consumo de ração e o desempenho dos leitões no período e na fase de crescimento.

O objetivo deste trabalho foi obter informações sobre diferentes formas de manejo de consumo de água e de ração no pós-desmame sobre a morfologia e o desenvolvimento enzimático intestinal de leitões recém-desmamados, visando compreender a relação destas alterações anátomo-fisiológicas com o desempenho no período.

\section{Material e Métodos}

Foram utilizados 32 leitões cruzados Large White $\mathrm{X}$ Landrace, machos castrados, desmamados aos $21 \pm 0,32$ dias de idade, com peso médio de $7,11 \pm 1,07 \mathrm{~kg}$. $\mathrm{O}$ experimento foi iniciado por ocasião da desmama e concluído oito dias após com o abate de todos os leitões.

Os animais foram alojados individualmente em 32 baias com 2,55 $\mathrm{m}^{2}$ (1,50 x 1,70 m). Foram utilizados bebedouros tipo taça (modelo SUIN N300), regulados para uma vazão de $600 \mathrm{~mL} /$ minuto, acoplados a um reservatório plástico individual com capacidade para 10 litros destinados à medição do consumo de água para cada animal.

O fornecimento de água e ração foi ad libitum. Os tratos alimentares foram feitos ao longo do dia, totalizando quatro refeições: às $7 \mathrm{~h} 30,11 \mathrm{~h} 30,14 \mathrm{~h} 30 \mathrm{e}$ 18 hs. As rações utilizadas no experimento foram formuladas visando atender ao mínimo as exigências estabelecidas pelo NATIONAL RESEARCH COUNCIL NRC (1988) para a fase (Tabela 1).

Os tratamentos correspondentes às dietas com inclusão de água obedeceram à relação de mistura de duas partes de ração para uma parte de água (v/v). Para os tratamentos cujas dietas foram confeccionadas com edulcorante, foi utilizado o produto comercial SUCRAM 200® (sacarina sódica), na dose de $200 \mathrm{~g} / \mathrm{t}$ de ração, e nos tratamentos em que a água de consumo foi oferecida com edulcorante utilizou-se o mesmo produto na dose de $200 \mathrm{~g} / 1000 \mathrm{~L}$ de água.

Os tratamentos experimentais foram: T1 - ração seca sem edulcorante e água de consumo sem edulcorante, T2 - ração seca sem edulcorante e água de consumo com edulcorante, T3 - ração seca com edulcorante e água de consumo sem edulcorante; T4 ração seca com edulcorante e água de consumo com edulcorante, T5 - ração úmida sem edulcorante e água de consumo sem edulcorante, T6 - ração úmida sem edulcorante e água de consumo com edulcorante, T7 - ração úmida com edulcorante e água de consumo sem edulcorante e T8 - ração úmida com edulcorante e água de consumo com edulcorante.

Foram avaliados o consumo diário de água e ração e as atividades intestinais (UA) da sacarase (EC 
796 Rev. bras. zootec.

Tabela 1 - Composição das rações experimentais (\%) Table 1 - Composition of the experimental diets (\%)

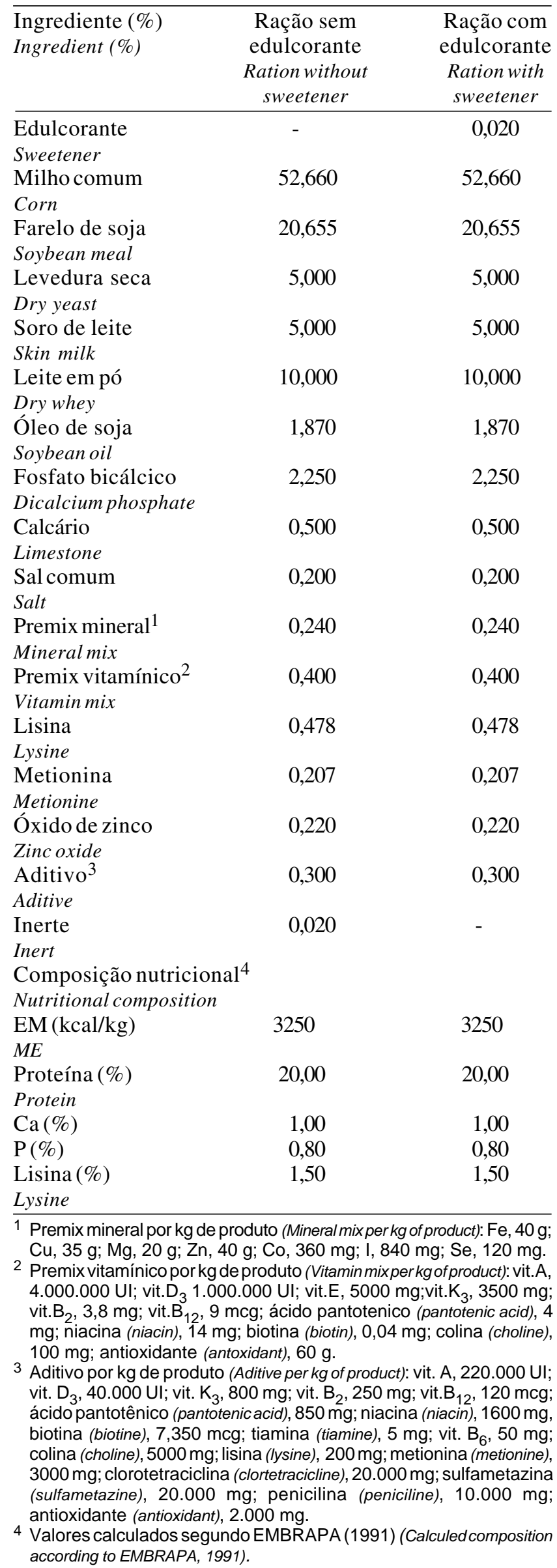

3.2.1.48), da maltase (EC 3.2.1.20) e da dipeptidase, o conteúdo de proteína da mucosa intestinal e as medidas mofométricas do duodeno e do jejuno (profundidade das criptas, altura das vilosidades e relação altura das vilosidades e profundidade das criptas).

Para a avaliação morfométrica intestinal, amostras de aproximadamente $1 \mathrm{~cm}$ da porção média do duodeno e $1 \mathrm{~cm}$ do jejuno médio de cada animal, de cada tratamento, foram coletadas e analisadas em um analisador de imagens KONTRON ELEKTRONIK (Video Plan). Para cada animal foram realizadas 30 medidas de altura de vilosidades e 30 de profundidade de criptas das porções do duodeno e do jejuno.

Para a determinação das enzimas intestinais, foram utilizadas porções correspondentes a $50 \%$ do comprimento total do intestino delgado (COLLINGTON et al., 1990). A determinação das atividades das enzimas sacarase (EC 3.2.1.48) e maltase (EC 3.2.1.20) foi definida pela dosagem da glicose liberada, respectivamente, por meio da hidrólise dos substratos sacarose e maltose pelas enzimas presentes no extrato bruto da mucosa (DAHLQVIST, 1964; KIDDER e MANNERS, 1980; SOTO, 1999). A quantificação da glicose liberada pela reação foi obtida pela utilização do "kit Glicose Enz - color" da Biodiagnóstica.

Para a determinação da atividade da dipeptidase, foi utilizado como substrato o dipeptídeo L-leucilglicina (LEU-GLI), em que a leucina liberada foi oxidada pela L-aminoácido oxidase (EC 1.4.3.2) em peróxido de hidrogênio (NICHOLSON e KIM, 1975).

O conteúdo de proteína do extrato da mucosa do duodeno foi determinado pela metodologia descrita por HARTREE (1972), sendo utilizado como padrão a soroalbumina bovina.

O delineamento experimental foi em blocos casualizados com oito tratamentos, num arranjo fatorial $2 \times 2 \times 2$, sendo duas formas de apresentação da ração, dois tipos de ração e dois tipos de água de consumo, com quatro repetições por tratamento, sendo adotado o seguinte modelo matemático:

$$
\begin{gathered}
\mathrm{Y}_{i j k l}=\mu+\mathrm{A}_{i}+\mathrm{B}_{j}+\mathrm{H}_{k}+\mathrm{g}_{l}+(\mathrm{AR})_{i j}+(\mathrm{AH})_{i k} \\
+(\mathrm{RH})_{j k}+(\mathrm{ARH})_{i j k}+\mathrm{e}_{i j k l}
\end{gathered}
$$

em que $\mathrm{Y}_{i j k}=$ valor da parcela com apresentação $i$, tipo de ração $j$, e tipo de água $k ; \mu=$ média geral; $\mathrm{A}_{i}=$ efeito da apresentação da ração $i(i=1,2)$; $\mathrm{B}_{j}=$ efeito do tipo de ração $j(j=1,2) ; \mathrm{H}_{k}=$ efeito tipo de água $k(k=1,2) ; \mathrm{g}_{l}=$ efeito do bloco $l(l=1,2,3$ e 4$)$; $(\mathrm{AR})_{i j}=$ efeito da interação entre a apresentação da ração $i$ e o tipo de ração $j$; $(\mathrm{AH})_{i k}=$ efeito da interação entre a apresentação de ração $i$ e o tipo de 
água $k ;(\mathrm{RH})_{\mathrm{jk}}=$ efeito da interação entre o tipo de ração $j$ e o tipo de água $k ;(\mathrm{ARH})_{i j k}=$ efeito da interação entre a apresentação de ração $i$, o tipo de ração $j$ e o tipo de água $k$; e ${ }_{i j k l}=$ erro aleatório associado a cada observação

As análises dos dados foram realizadas por intermédio do programa SAEG (UNIVERSIDADE FEDERAL DE VIÇOSA - UFV, 1997), sendo as médias dos fatores comparadas pelo teste Tukey a $5 \%$.

\section{Resultados e Discussão}

Na Tabela 2 pode ser observado o consumo diário de água e ração para cada grupo. Os valores indicam a ausência de diferença entre os fatores $(\mathrm{P}>0,05)$, contrariando os resultados obtidos por STOCKILL (1990), para um consumo mais elevado para água tratada com edulcorante, e os resultados superiores de consumo de ração, citado por HEIMIG (1996) e FREITAS et al. (1997), para dietas com alto teor de umidade. Também não foi observada a ocorrência de interação entre os fatores.

Na Tabela 3 estão apresentadas as médias da altura das vilosidades e da profundidade das criptas e a relação altura das vilosidades e profundidade das criptas (relação V:C) das porções médias do duodeno e do jejuno para os fatores estudados.

Tabela 2 - Médias e desvios-padrão do consumo diário de água e do consumo diário de ração

Table 2 - Means and standard deviations of daily water intake and daily feed intake

\begin{tabular}{lcc}
\hline $\begin{array}{l}\text { Fatores } \\
\text { Factors }\end{array}$ & $\begin{array}{c}\text { Consumo diário } \\
\text { de água }(\mathrm{mL}) \\
\text { Daily water } \\
\text { intake }(\mathrm{mL})\end{array}$ & $\begin{array}{c}\text { Consumo diário } \\
\text { de ração }(\mathrm{g}) \\
\text { Dailyfeed } \\
\text { intake }(\mathrm{g})\end{array}$ \\
\hline $\begin{array}{l}\text { Dieta seca } \\
\text { Dry diet }\end{array}$ & $60^{\mathrm{a}} \pm 17$ \\
$\begin{array}{l}\text { Dieta úmida } \\
\text { Humid diet }\end{array}$ & $343^{\mathrm{a}} \pm 80$ & $79^{\mathrm{a}} \pm 24$ \\
$\begin{array}{l}\text { Ração sem edulcorante } \\
\text { Ration without sweetener } \\
\text { Ração com edulcorante } \\
\text { Ration with sweetener }\end{array}$ & $364^{\mathrm{a}} \pm 80$ & $78^{\mathrm{a}} \pm 8$ \\
$\begin{array}{l}\text { Água sem edulcorante } \\
\text { Water without sweetener }\end{array}$ & $310^{\mathrm{a}} \pm 97$ & $58^{\mathrm{a}} \pm 25$ \\
$\begin{array}{l}\text { Água com edulcorante } \\
\text { Water with sweetener }\end{array}$ & $343^{\mathrm{a}} \pm 100$ & $69^{\mathrm{a}} \pm 19$ \\
$\begin{array}{l}\text { Coeficiente de variação } \\
\text { Coefficient of variation }\end{array}$ & 27,13 & $68^{\mathrm{a}} \pm 24$ \\
$\begin{array}{l}\text { Em cada coluna, para cada fator, médias seguidas da mesma letra } \\
\text { não diferem (P>0,05) pelo teste Tukey. } \\
\text { For each factor, in each column, means with the same letters do not } \\
\text { differ (P>.05) by Tukey test. }\end{array}$ & 31,05 \\
\end{tabular}

Os valores obtidos mostraram diferença $(\mathrm{P}<0,05)$ na altura das vilosidades do duodeno para os fatores apresentação da ração e tipo de ração, sendo superior nos grupos tratados com ração úmida e com edulcorante.

Para a profundidade das criptas do duodeno e do jejuno e para a altura das vilosidades do jejuno, não foram verificadas diferenças $(\mathrm{P}>0,05)$ nos fatores, entretanto, foram observados valores superiores para os grupos que receberam ração úmida e ração com edulcorante, com exceção da profundidade da cripta do jejuno para aqueles tratados com ração com edulcorante.

Os resultados foram semelhantes aos relatados por DEPREZ et al. (1987), em que leitões desmamados tratados com dietas secas apresentaram redução na altura das vilosidades. TEODORO (1997), entretanto, não observou diferença significativa para a altura das vilosidades do duodeno e do jejuno para leitões que receberam dietas farelada e extrusada seca e extrusada úmida.

Os resultados sugerem que as dietas úmidas aparentemente são mais apropriadas fisiologicamente para leitões desmamados, concordando com os resultados obtidos por HEIMIG (1996).

As maiores medidas da altura das vilosidades a favor dos animais que receberam ração com edulcorante não corresponderam ao menor consumo de ração observado para o grupo, contradizendo a hipótese de que maior consumo de ração no período pós-desmame tem ação estimulante sobre a integridade morfológica da parede intestinal e sobre a maturação do epitélio (KELLY et al., 1991b; MAKKING et al., 1994).

Quanto à relação V:C do duodeno, os resultados mostraram superioridade $(\mathrm{P}<0,05)$ para os animais que receberam ração com edulcorante, porém, para a relação $\mathrm{V}: \mathrm{C}$ no jejuno, não foi verificada diferença para nenhum fator $(P>0,05)$. De acordo com os resultados apresentados na Tabela 3 , é valido considerar que, mesmo não significativos os demais valores da relação V:C, uma diferença prevaleceu a favor do grupo tratado com ração úmida.

Os resultados das atividades das enzimas intestinais (sacarase, maltase e dipeptidase) e do conteúdo de proteína da porção média da mucosa do intestino delgado, de acordo com os fatores, estão demonstrados na Tabela 4.

Para o conteúdo de proteína da mucosa, não foi observada diferença $(\mathrm{P}>0,05)$ entre os fatores estudados.

A atividade da sacarase, expresssa em $\mathrm{UA} / \mathrm{g}$ de 
798 Rev. bras. zootec.

Tabela 3 - Médias e desvios-padrão da altura das vilosidades (ALTVILO), profundidade das criptas (PROFCRIP) e relação da altura das vilosidades e da profundidade das criptas (V:C) do duodeno e do jejuno médio, aos 29 dias de idade

Table 3 - Means and standard deviations of intestinal villi height (VILHEIGHT), crypt depth (CRY DEPTH) and relation between villi height and crypt depth of middle duodenum and jejunum at 29 days of age

\begin{tabular}{|c|c|c|c|}
\hline $\begin{array}{l}\text { Fatores } \\
\text { Factors }\end{array}$ & $\begin{array}{l}\text { ALTVILO }(\mathrm{mm}) \\
\text { VILHEIGHT }(\mathrm{mm})\end{array}$ & $\begin{array}{l}\text { PROFCRIP }(\mathrm{mm}) \\
C R Y D E P T H(\mathrm{~mm})\end{array}$ & $\begin{array}{l}\mathrm{V}: \mathrm{C} \\
V: C\end{array}$ \\
\hline & \multicolumn{3}{|c|}{$\begin{array}{l}\text { Duodeno } \\
\text { Duodenum }\end{array}$} \\
\hline $\begin{array}{l}\text { Dieta seca } \\
\text { Drydiet }\end{array}$ & $258,42^{b} \pm 59,93$ & $155,51^{\mathrm{a}} \pm 30,65$ & $1,65^{\mathrm{a}} \pm 0,18$ \\
\hline Dieta úmida & $292,78^{a} \pm 45,15$ & $172,58^{\mathrm{a}} \pm 27,47$ & $1,70^{\mathrm{a}} \pm 0,12$ \\
\hline $\begin{array}{l}\text { Ração sem edulcorante } \\
\text { Ration without sweetener }\end{array}$ & $257,33^{\mathrm{b}} \pm 56,32$ & $160,28^{a} \pm 34,26$ & $1,60^{\mathrm{b}} \pm 0,14$ \\
\hline $\begin{array}{l}\text { Ração com edulcorante } \\
\text { Ration with sweetener }\end{array}$ & $293,33^{\mathrm{a}} \pm 49,15$ & $167,28^{a} \pm 25,61$ & $1,75^{\mathrm{a}} \pm 0.13$ \\
\hline $\begin{array}{l}\text { Água sem edulcorante } \\
\text { Water without sweetener }\end{array}$ & $288,02^{\mathrm{a}} \pm 48,65$ & $172,47^{\mathrm{a}} \pm 23,33$ & $1,66^{\mathrm{a}} \pm 0,18$ \\
\hline $\begin{array}{l}\text { Água com edulcorante } \\
\text { Water with sweetener } \\
\text { Coeficiente de variação } \\
\text { Coefficient of variation }\end{array}$ & $263,17^{\mathrm{a}} \pm 59,69$ & $155,62^{\mathrm{a}} \pm 38,49$ & $1,68^{\mathrm{a}} \pm 0,13$ \\
\hline & & $\begin{array}{l}\text { Jejuno } \\
\text { Jejunum }\end{array}$ & \\
\hline $\begin{array}{l}\text { Dieta seca } \\
\text { Drydiet }\end{array}$ & $216,04^{\mathrm{a}} \pm 53,95$ & $128,78^{a} \pm 25,36$ & $1,67^{\mathrm{a}} \pm 0,15$ \\
\hline $\begin{array}{l}\text { Dieta úmida } \\
\text { Humid diet }\end{array}$ & $245,54^{\mathrm{a}} \pm 37,75$ & $143,78^{a} \pm 23,68$ & $1,72^{\mathrm{a}_{ \pm}} \mathbf{0 , 2 1}$ \\
\hline $\begin{array}{l}\text { Ração sem edulcorante } \\
\text { Ration without sweetener }\end{array}$ & $225,88^{a} \pm 52,97$ & $136,13^{\mathrm{a}} \pm 30,44$ & $1,65^{\mathrm{a}} \pm 0,16$ \\
\hline $\begin{array}{l}\text { Ração com edulcorante } \\
\text { Ration with sweetener }\end{array}$ & $235,70^{\mathrm{a}} \pm 44,12$ & $135,81^{\mathrm{a}} \pm 20,57$ & $1,73^{\mathrm{a}} \pm 0,20$ \\
\hline $\begin{array}{l}\text { Água sem edulcorante } \\
\text { Water without sweetener }\end{array}$ & $240,28^{a} \pm 35,58$ & $137,05^{\mathrm{a}} \pm 20,93$ & $1,76^{\mathrm{a}} \pm 0,16$ \\
\hline $\begin{array}{l}\text { Água com edulcorante } \\
\text { Water with sweetener }\end{array}$ & $221,30^{\mathrm{a}} \pm 57,87$ & $134,90^{\mathrm{a}} \pm 29,88$ & $1,63^{\mathrm{a}} \pm 0,18$ \\
\hline $\begin{array}{l}\text { Coeficiente de variação } \\
\text { Coefficient of variation }\end{array}$ & 19,81 & 17,89 & 11,35 \\
\hline
\end{tabular}

Em cada coluna, para cada fator, médias seguidas da mesma letra não diferem $(P>0,05)$ pelo teste Tukey.

For each factor, in each column, means with the same letters do not differ $(P>05)$ by Tukey test.

proteína, foi maior somente $(\mathrm{P}<0,05)$ para o grupo que recebeu água sem edulcorante. Quanto à atividade da sacarase, expressa em UA/g de mucosa, também verificou-se diferença $(\mathrm{P}<0,05)$ a favor do grupo tratado com água sem edulcorante. É importante ressaltar que a composição química da sacarina sódica não apresenta semelhança com um carboidrato como a sacarose. Para a atividade da maltase, expressa em UA/g de proteína e em UA/g de mucosa, foi demonstrada diferença para o grupo que recebeu água sem edulcorante $(\mathrm{P}<0,05)$, entretanto, para a atividade da dipeptidase, não foram observadas diferenças entre os fatores $(\mathrm{P}>0,05)$.

Os valores do conteúdo da proteína da mucosa apresentaram-se próximos aos determinados por
KELLY et al. (1991ab), PLUSKE et al. (1996ab) e SOTO (1999). PLUSKE et al. (1996c) verificaram que o menor conteúdo protéico da mucosa, no período subseqüente ao desmame, se deve à baixa quantidade de energia ingerida no período, independente do tipo de dieta.

Os níveis de atividade da sacarase, expressos em UA/g de proteína e em UA/g de mucosa, encontraramse dentro da faixa de valores obtidos por SOTO (1999).

A atividade da maltase também foi semelhante à descrita para a sacarase. Os resultados identificaram-se com os valores encontrados por SOTO (1999). Os valores da maltase, expressos em UA/g de proteína, todavia, foram superiores aos resultados obtidos por KELLY et al. (1991ab) e NUNEZ et al. (1996). 
SILVA et al.

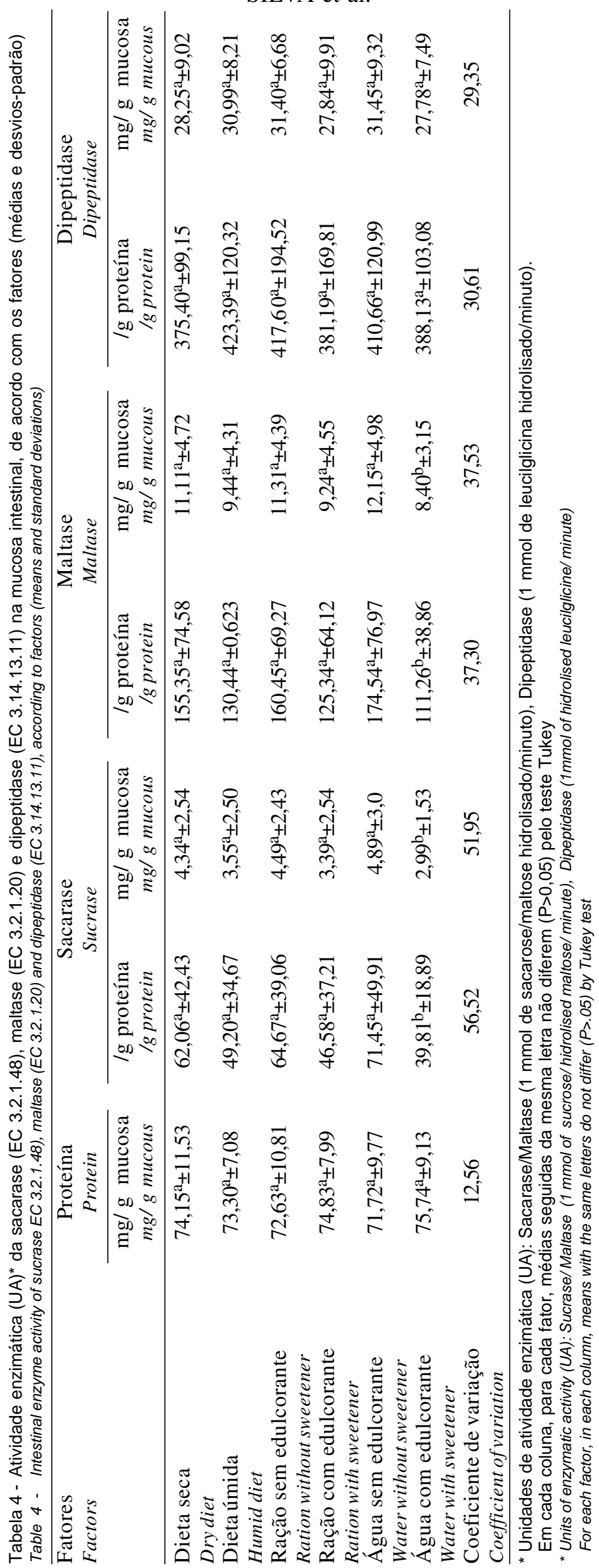


800 Rev. bras. zootec.

Atribui-se que fatores como metodologias diferentes utilizadas, formas de expressão da atividade enzimática, idade do desmame, quantidade de alimento consumido no pré e no pós-desmame, peso vivo e status sanitário, entre outros, podem exercer importante influência nos resultados (PLUSKE et al., 1997).

KELLY et al. (1991b) concluíram que a idade fisiológica e a idade cronológica podem não corresponder quanto ao desenvolvimento enzimático. KITTS et al. (1956), entretanto, verificaram que o tamanho fisiológico exerce influência sobre o desenvolvimento enzimático.

A associação da menor altura das vilosidades e da maior profundidade das criptas, observada no período pós-desmame, com a redução na atividade das enzimas intestinais, ligadas aos enterócitos na região do brush border, foi amplamente estudada por HAMPSON (1986), HAMPSON e KIDDER (1986) e PLUSKE et al. (1996b), porém, provavelmente influenciado por fatores adversos, esta relação nem sempre tem obedecido a hipótese da associação citada.

Os níveis mais elevados de sacarase e maltase para o fator água sem edulcorante não apresentaram relação com o consumo de ração observado no período para o tratamento. Este resultado, contrariamente, não se identificou com os resultados obtidos por KELLY et al. (1991b), que observaram maior atividade das enzimas intestinais para animais que consumiram maior quantidade de ração no pós-desmame.

\section{Conclusões}

No período subseqüente ao desmame de 21 dias, a ultra-estrutura da mucosa intestinal foi influenciada positivamente, quando os leitões foram tratados com dietas úmidas e rações com edulcorante.

O perfil enzimático no 8 o dia pós-desmame foi pouco favorecido pelos fatores apresentação da dieta e presença ou ausência de edulcorante na ração e na água, não obstante, quando a água foi oferecida sem edulcorante, os níveis de sacarase e maltase foram mais elevados.

O desenvolvimento anátomo-fisiológico do intestino no 8o dia pós-desmame, para leitões desmamados aos 21 dias, parece estar relacionado a muitos outros fatores, não dependendo somente da apresentação da dieta (seca ou úmida) e dos estímulos de consumo de água e ração com o uso de edulcorantes.

Os objetivos do trabalho visavam obter, diante dos tratamentos dispensados, informações sobre o desenvolvimento anatômico e enzimático do intestino durante o período considerado mais crítico para o desmamado. É possível supor que avaliações sob períodos pós-desmame mais prolongados venham determinar resultados diferentes dos obtidos.

\section{Referências Bibliográficas}

CERA, K.R., MAHAN, D.C., CROS, R.F. et al. 1988. Effect of age, weaning and postweaning diet on small intestinal growth and jejunal morphology in young swine. J. Anim. Sci., 66(2):574-584.

CERA, K.R., MAHAN, D.C., REINHART, G.A. 1990. Effect of weaning, week postweaning and diet composition on pancreatic and small intestinal luminal lipase response in young swine. J. Anim. Sci., 68(2):384-391.

COLlingtON, G.K., PARKER, D.S., ARMSTRONG, D.G. 1990. The influence of inclusion of either an antibiotic or a probiotic in the diet on the development of digestive enzyme activity in the pig. Br. J. Nutr., 64(1):59-70.

CUNHA, T.J. 1977. Swine feeding and nutrition. New York: Academic Press. p.183-189.

DAHLQVIST, A. 1964. Method for assay of intestinal disaccharidases. Anal. Biochem., 7(1):18-25.

DEPREZ, P., DEROOSE, J.P., VAN DEN HENDE, C. et al. 1987. Liquid versus dry feeding in weaned piglets: the influence on small intestinal morphology. J. Vet. Med. Ser., 34(6):254-259.

EMBRAPA. 1991. Tabela de composição química e valores energéticos para suínos e aves. 3.ed. Concórdia:CNPSA. 97p. (Documentos, 19).

FREITAS, H.T, FERREIRA, A.S., DONZELE, J.L. et al. 1997. Manejo para desmame de leitões aos 21 dias de idade. R. Bras. Zootec., 26(4):753-758.

HAMPSON, D.J 1986. Alterations in piglet small intestine structure at weaning. Res. Vet. Sci., 40(1):32-40.

HAMPSON, D.J., KIDDER, D.E. 1986. Influence of crep feeding and weaning on brush border enzyme activities in piglet small intestine. Res.Vet. Sci., 40(1):24-31.

HARTREE, E.F. 1972. Determination of protein: a modification of the Lowry method that gives a linear photometric response. Anal. Biochem., 48:422-427.

HEIMIG, D. 1996. Why $78 \%$ of feeds choose liquid system. Pigs, 12(6):9.

KELLY, D., SMITH, J. A., MACRAKEN, K. J. 1991a. Digestive development of the early weaned pig. 1. Effect of continous nutrient supply on the development of the digestive tract and on changes in digestive enzyme activity during the first week post-weaning. Br. J. Nutr., 65(2):169-180.

KELLY, D., SMITH, J. A., MACRAKEN, K. J. 1991b. Digestive development of the early weaned pig. 2. Effect of level of food intake on digestive enzyme activity during the immediate post weaning period. Br. J. Nutr., 65(2):181-188.

KIDDER, D.E., MANNERS, M.J. 1980. The level and distribution of carbohydrases in the small intestine mucosa of pig from 3 weeks of age to maturity. Br. J. Nutr., 43(2):141-153.

KITTS, W.D., BAILEY, C.B., WOOD, A.J. 1956. The development of phase digestive enzyme system of the pig during its preweaning phase of growth. A. Pancreatic amylase and lipase. Can. J. Agric. Sci., 36:45-50. 
MAENZ, D.D., PATIENCE, J.F., WOLYNETZ, M.S. 1993. Effect of water on the performance of newly weaned pigs offered medicated and unmedicated feed. Can. J. Anim. Sci., 73(3):669-672.

MAKKING, C.A., NEGULESCU, G. P., GUIXIN, Q. et al. 1994. Effect of dietary protein source on feed intake, growth, pancreatic enzyme activities and jejunal morphology in newly weaned piglets. Br. J. Nutr., 72(3):353-368.

NICHOLSON, J.A., KIM, Y.S. 1975. A one-step L-amino acid oxidase assay for intestinal peptide hydrolase activity. Anal. Biochem., 63:110-117.

NATIONAL RESEARCH COUNCIL - NRC. 1988. Nutrient requirement of swine. 9.ed. Washington: National Academic Press. 93p.

NUNEZ, M.C., BUENO, J.D., AYDARTE, M.V. et al. 1996. Dietary restriction induces biochemical and morphometric changes in the small intestine of nursing piglets. J. Nutr., 126(4):933-944.

PEKAS, J.C. 1991. Digestion and absortion capacity and their development. In: MILLER, E.R., ULLREY, D.E., LEWIS, A.J. Swine Nutrition. Stonehan: Butteerworth-Heineman, p.37-73.

PLUSKE, J.R., THOMPSON, M.J., ATWOOD, C.S. et al. 1996a. Maintenance of villus height and crypt depth, and enhancement of disaccharide digestion and monosaccharide absortion, in piglets fed on cows' whole milk after weaning. Br. J. Nutr., 76(3):409-422.

PLUSKE, J.R., WILLIANS, I.H., AHERNE, F.X. 1996b. Maintenance of villus height and crypt depth in piglets by providing continuous nutrition after weaning. Anim. Sci., 62(1):131-144.

PLUSKE, J.R., WILLIANS, I.H., AHERNE, F.X. 1996c. Villus height and crypt depth in piglets in response to increases in the intake of cows' milk after wening. Anim. Sci., 62(1):145-158.

PLUSKE, J.R.,HAMPSON, D.J., WILLIAMS, D.L. et al. 1997. Factors influencing the strutured and function of the small intestine in the weaned pig: a review. Livest. Prod. Sci., 51(1-3):215-236.
SOBESTIANSKY, J., WENTZ, I. 1985. Aspectos sanitários relacionados com o leitão desde o nascimento até o abate. In: SOBESTIANSKY, J., WENTZ, I., SILVEIRA, P.R.S. et al. (Eds.) Manejo em suinocultura: aspectos sanitários, reprodutivos e de meio ambiente. Concórdia: EMBRAPACNPSA, 1.ed. p.11-61.

SOTO, W.L.C. Digestibilidade da levedura desidratada (Saccharomyces cerevisae) e efeitos da sua utilização sobre a morfologia intestinal, atividade das enzimas digestivas $e$ desempenho de suínos. Jaboticabal, SP: UNESP, 1999. 82p. Tese (Doutorado em Zootecnia) - Faculdade de Ciências Agrárias e Veterinárias/Universidade Estadual Paulista, 1999.

STOCKILL, P. 1990.Water: whey it should not be the neglected nutrient for pigs. Feed Int., 11(10):10-18.

TEODORO, S.M. Desempenho e morfologia intestinal de leitões alimentados com dietas fareladas ou extrusada seca e úmida. Botucatu, SP: UNESP, 1997.68p. Dissertação (Mestrado em Zootecnia) - Faculdade de Medicina Veterinária e Zootecnia/ Universidade Estadual Paulista, 1997.

TOPLIS, P., TIBBLE, S. 1994. Nutritional limitations of postweaning growth explored. Feedstuffs, 25:12-13.

UNIVERSIDADE FEDERAL DE VIÇOSA - UFV. 1997. SAEG - Sistema de análises estatísticas e genéticas. Versão 7.1. Viçosa, MG. 150p (Manual do usuário)

WHITTEMORE, C.T. 1993. The science and practice of the pig. Essex: Longman Scientific e Technical. 661p.

Recebido em: 16/06/00

Aceito em: 12/01/01 